\title{
EI Derecho Romano como Elemento de Armonización del Nuevo Derecho Común Europeo
}

\author{
Alfonso Murillo Villar \\ Professor catedrático de Direito Romano na \\ Universidade de Burgos (Espanha) \\ almuvi@ubu.es
}

Resumen: En el ámbito de la Unión Europea el derecho está conformado por una constelación de ordenamientos autónomos que necesitan de una aproximación. Como todos los ordenamientos jurídicos son de base romanística, especialmente los de la Europa continental, el derecho romano debe de tener un papel transcendental en su futura armonización, sin que por ello se suprima la diversidad jurídica propia de cada pueblo de los que conforma la Unión Europea.

Palabras clave: Unión Europea. Armonización jurídica. Derecho Romano. Derecho común europeo.

El 1 de enero de 2007 nacía una nueva Unión Europea, integrada por 27 miembros con la incorporación de Bulgaria y Rumania y 485 millones de ciudadanos. Ante este hecho quizás fuera oportuno reflexionar sobre los orígenes de la "vieja" Europa. Reflexionar sobre dichos orígenes conviene hacerlo desde cualquier perspectiva, y ello porque la formación de Europa es un problema histórico, complejo, con muchos perfiles y matices, dándonos cuenta enseguida que la aportación romana fue decisiva en este largo y discutido proceso de formación de Europa.

Con ello quiero decir que una reflexión histórica es hoy más necesaria que nunca, porque difícilmente podemos saber hacia dónde vamos si no tenemos algunas certezas acerca de dónde venimos. Ser europeo es un predicado atribuible hoy en día, por antonomasia, a unos, aproximadamente, 485 millones de personas. Con él se designa la condición de los nacionales de los Estados miembros que constituyen la Unión Europea. Este apelativo de europeo significa no sólo la pertenencia a un espacio geográfico, sino también la forma de existencia propia de quienes se caracterizan por gozar de tres elementos esenciales: 1.- de un común patrimonio de respeto a los 
derechos y libertades fundamentales de la persona; 2.- de unas estructuras políticas democráticas y 3.- de unas economías sociales de mercado

En opinión de Paricio Aucejo, este acervo que distingue a la Europa Comunitaria no tiene sus raíces en los grandes cambios vividos en las últimas décadas, sino en una idea elaborada a lo largo de los siglos, en ocasiones sostenida incluso de forma utópica. Como decía Paul Hazard: E uropa es un pensamiento que no se contenta nunca ${ }^{2}$. Ello explica que innumerables literatos, filósofos, políticos, juristas y pensadores en general, hayan experimentado a lo largo del tiempo el secular pálpito de la llamada de Europa. Se ha pasado de un mundo de meros ideales a una realidad que, aún inacabada, ha conseguido notorios logros concretos y se encuentra, cualitativa y cuantitativamente, en continua expansión.

El proyecto comunitario, surgido hace más de cincuenta años, es uno de los grandes inventos políticos del pasado siglo XX si bien en origen tuvo una clara finalidad económico-comercial. Por primera vez en la historia de nuestro continente, este proyecto no es el resultado de la hegemonía militar o política de una potencia dominante, sino el fruto de un progresivo proceso de puesta en común de los distintos intereses nacionales. Se observa que la Europa comunitaria vive un largo periodo de paz y prosperidad, y tal vez se deba a que los gobiernos de sus Estados miembros no obran de manera independiente los unos de los otros sino que se interrelacionan e interactúan por medio de la Comunidad.

La Unión Europea, como consecuencia de las sucesivas ampliaciones, se ha convertido en una entidad multicultural, vigorosa en su diversidad y pluralidad histórica. En la actualidad cuenta con veintisiete estados miembros, y dicha cifra es muy probable que se amplíe a lo largo de los próximos años con la paulatina incorporación de nuevos países que ya han presentado su candidatura a la adhesión, como por ejemplo Turquía. Por consiguiente, es posible que estemos en presencia del comienzo de un mundo nuevo, distinto del organizado por las actuales formaciones estatales. Europa es un proyecto ambicioso, de difícil concreción y con un camino todavía muy largo por recorrer.

Hoy en día no basta, pues, con ser europeo sino que lo decisivo es saber ser europeo. Ello se concreta mediante tres actitudes básicas: 1.- tener un conocimiento esencial del pasado y de la organización actual de la colectividad europea; 2.- reconocer

\footnotetext{
' Vid. PARICIO AUCEJO, P., Unión europea y sociedad civil, Valencia 2002, 17 ss.

2 PAUL HAZARD (Noordpeene Village, 1878 - París, 1944), historiador y ensayista francés. Fue catedrático en la Universidad de Lyon y profesor en La Sorbona; en 1925 alcanzó la cátedra de literatura moderna y comparada. Su obra principal L a Crisis de la conciencia europea de 1680 a 1715, ha alcanzado gran repercusión en la historiografía moderna.
} 
el valor de los principios en que se funda; y 3.- tomar la decisión de contribuir a su consolidación y mejora. En todo ello, como resulta obvio, tiene mucho que decir Roma, su historia y su ordenamiento jurídico, del cual desciende la inmensa mayoría de los ordenamientos jurídicos europeos vigentes.

Por desgracia, pocos son los europeos que se sienten ciudadanos de la Unión con la misma normalidad, al menos, con que lo experimentan de su ciudadanía nacional. Esta desafección ciudadana supone un riesgo evidente para la construcción europea, pues pone en peligro tanto su porvenir como su propia supervivencia como proyecto político. En estos momentos, la Unión Europea carece, en propiedad y exclusividad, de ciertos elementos imprescindibles para ser un Estado3: soberanía, diplomacia, defensa, capacidad de decisión, y muy especialmente, quiero resaltarlo con énfasis, de un ordenamiento jurídico unitario que evite la diversidad legislativa, punto clave en el proceso de formación de cualquier estado.

Ahora bien, existen aspectos culturales en los que la diversidad es un punto fuerte a favor de Europa, pero creo que en el jurídico no es lo más apropiado. La pluralidad de ordenamientos puede representar un obstáculo a la libre circulación de personas, mercancías, capitales y servicios, ya que genera incertidumbre acerca del derecho aplicable y, en los contratantes, dificultades para sopesar las consecuencias de sus propios actos. La Unión Europea tiene entre sus deberes la aproximación de las legislaciones allí donde la variedad plantee obstáculos al mercado. Sin embargo, la armonización aún no ha tenido lugar, y especialmente en el ámbito del derecho privado el "derecho europeo" continúa siendo una constelación de ordenamientos autónomos, coordinados según el sistema del derecho internacional privado y la cooperación judicial. Esta circunstancia se debe a que al jurista aún se le forma en su derecho nacional, pues "no existe todavía el jurista europeo", por ello, que el derecho romano siga siendo un importante "vínculo vivo en la formación de todos los juristas"4.

Por tanto, es insoslayable partir de la premisa de que la Unión Europea es un proyecto en la historia. Como tal, no ha sido una idea que haya surgido espontáneamente en el siglo XX ni siquiera fue exclusiva de él. Ha sido una utopía constante en el pensamiento europeo que encuentra su fundamento último en la historia de nuestro viejo continente. Hacia el año 900 a.C., el poeta Hesiodo, en la Teogonía o El nacimiento de los Dioses, utilizaba por primera vez el nombre de Europa, tal y como después lo hará Hipócrates, quien la describe en comparación

\footnotetext{
${ }^{3}$ PARICIO AUCEJO, Unión europea y sociedad civil, cit., 47 ss.

${ }^{4}$ ZIMMERMANN, R., Europa y el Derecho romano (estudio introductorio y traducción de I. Cremades), Madrid, 2009, 12 ss. y 49.
} 
a Asia, y Herodoto. Así, pues, fueron los griegos los que identificaron a Europa como un espacio geográfico diverso, con un mosaico de paisajes y climas y una pluralidad de razas, de las que surgirían posteriormente una gran diversidad de lenguas y culturas.

La Antigüedad clásica difundió el nombre de Europa, ligado al mundo de la mitología (en un relato, según el cual, una joven y bella fenicia, hija de Agenor - que era rey de T iro y F enicia- fue raptada por Zeus, metamorfoseado en un gran toro blanco, y conducida a $\mathrm{C}$ reta, donde se convertiría en reina y madre de los reyes de la dinastía de M inos). Por otra parte, también la Biblia, capítulos 9 y 10 del Génesis, creó el mito de Jafet, según el cual los tres hijos de Noé se repartieron el mundo: para Sem, Asia; para Cam, Africa; y todos los descendientes de la línea de Jafet poseyeron Europa. Esta mítica tripartición del mundo fue la que dominó la cosmovisión antigua y medieval.

Herederos de la grandeza de los griegos, los romanos conservaron una cierta idea geográfica de Europa. Desde Polibio a Ptolomeo, desde Estrabón a Plinio el Viejo, geógrafos e historiadores fijaron el límite de Europa en el océano Atlántico, (contemplando a Gran B retaña como una isla europea, señalando la frontera en e D on, y desconociendo si E uropa era insular). Europa comprendía para ellos una diversidad de territorios y de pueblos: Iberia, Céltica, la Bretaña, el Danubio, los Germanos, los Sármatas, la Tracia, la Iliria, Grecia, etc., los desconocidos países escandinavos, y la vasta planicie que se extiende desde el Báltico al Don.

Pero verdaderamente sólo se comenzó a tomar conciencia de una cierta identidad de Europa en el siglo VIII, cuando, con motivo de la invasión musulmana, se produjo el choque entre esta civilización y la cristiana ${ }^{5}$. Así se refleja en una crónica mozárabe del año 754 en la que se denomina "europeos" (europenses) a los ciudadanos que se enfrentaron a los Árabes en Poitiers, designando de este modo a la comunidad continental que se defendía contra el enemigo exterior. Se define así una conciencia de Europa frente al Islam.

Otro dato curioso se produce cuando el rey franco Carlomagno, establecido en Aquisgrán, convertido en el árbitro de Occidente, al recibir el día de Navidad del año 800, del Papa León III, la corona Imperial, fue saludado con las palabras "Rex. Pater Europae", y en los Anales de Fulda se reflejó la identidad de "Europa vel Regnum Carolum": Europa o el Reino de Carlos. Pero fue en época medieval cuando en las Universidades se elaboró el llamado Ius commune o Derecho Común a partir del derecho romano y derecho canónico, que se extendió por toda Europa, comenzando un verdadero proceso de recepción del derecho romano y su implantación e influencia en los grandes ordenamientos jurídicos de la Europa continental.

${ }^{5}$ Vid. TORRENT, A., Fundamentos del derecho europeo. Ciencia del derecho: derecho romano-ius commune-derecho europeo, Madrid, 2007, 184 ss. 
Europa es algo más que símbolos, mitos y ritos, y sobre todo si la diversidad es uno de sus elementos más característicos, que si bien es grandemente formativo y digno de conservar, a nadie escapa las dificultades que ello plantea a la hora de conseguir una Unión Europea sólida y con unas bases comunes, a lo cual sin duda puede por la vía jurídica y superando la dispersión normativa colaborar el derecho romano de cara a la armonización de todos los cuerpos legales europeos.

En los últimos tiempos se ha intentado aprobar una Constitución Europea, sustituida finalmente Tratado de Lisboa (2009), cuyo ideólogo fue Valerie Giscard D’Estaing (ex-presidente de la República Francesa), y en la que siempre se impidió que constara cualquier alusión al pasado romano y a las raíces cristianas, sin embargo, existe un hecho anecdótico que hace directa alusión a dicho pasado.

La bandera europea es azul, con doce estrellas dispuestas en círculo. Esta decisión fue adoptada en mayo de 1986 y acogió el diseño que desde 1955 pergeñó el Consejo de Europa para convertirlo en bandera de todos los europeos. Un artista alsaciano llamado Arsenio Heitz se presentó al concurso de ideas convocado por el Consejo de Europa para diseñar la divisa, la bandera. Y diseñó una bandera azul con 12 estrellas, como es ahora. Lo más curioso es que en verano del 2004 el tal Heitz, reveló que fue una inspiración divina en la que sobre un fondo azul colocó las 12 estrellas de la corona de la Inmaculada Concepción: "Corona stellarum duodecim". Por tanto, resulta curioso que mientras la Unión Europea se esfuerza por parecer una institución laica, uno de sus símbolos tiene reminiscencias católicas (cristianas).

La bandera europea no representa con sus estrellas a cada uno de sus estados miembros como sí ocurre con la bandera americana (EEUU), y además tampoco parece que interese destacar toda esta simbología de cariz cristiano pues Turquía, país no cristiano, puede que algún día forme parte de la Unión Europea. Por si hubiera dudas sobre la inspiración cristiana de la bandera, en la catedral de Estrasburgo se colocó un vitral (vidriera) tres días después de aprobarse la bandera azul por el Consejo de Europa, el 11 de diciembre de 1955, con la Virgen coronada por la corona stellarum duodecim. Además, la divisa, la bandera europea se aprobó por primera vez el 8 de diciembre de 1955, fiesta de la Inmaculada Concepción por más señas. ¿Casualidad? No lo creo.

Volviendo a la cuestión que nos ocupa conviene precisar que la fecha de la Coronación de Carlomagno (Navidad 800 d.C.), se revela incorrecta como punto de partida de una historia de la jurisprudencia o ciencia jurídica europea. Es preciso regresar unos siglos antes, a la jurisprudencia romana. Este retraso aparece como indispensable cuando se tiene conciencia de que el material romano fue tomado en consideración en la Edad Media no sólo por su contenido normativo, sino y, sobre todo, por los instrumentos conceptuales de los que está entretejido y, más aún, por su valor metodológico ${ }^{6}$.

\footnotetext{
${ }^{6}$ CANNATA, C.A., Historia de la ciencia jurídica europea (trad. de L. Gutiérrez-Masson), Madrid, 1996, 17.
} 
De este modo puede afirmarse que la historia de la ciencia jurídica europea comenzó antes que la historia de Europa. Esta afirmación en absoluto es absurda ya que Europa es una realidad de orden cultural: representa un conjunto de elementos culturales que se han concretado en un espacio geográfico dado. Ciertamente, el derecho romano no podía revestir, en época romana, un carácter europeo. Dicho carácter lo adquirió después de la formación de Europa, pero esto sucedió sin que por ello perdiera su identidad, pues siguió siendo individualizado siempre como derecho romano ${ }^{7}$.

Europa se encuentra actualmente en una encrucijada jurídica al querer construir una realidad supraestatal entre todos los pueblos del viejo continente ${ }^{8}$. Lo que no se debe olvidar, por ser esencial, es que uno de los instrumentos de unión entre sus pueblos es el de compartir un mismo orden normativo. El derecho, que siempre ha sido un producto histórico, es quien ha de facilitar en estos momentos el que Europa configure de la forma más acertada posible su propia realidad. Es imposible construir la Unión Europea desvinculándola de su pasado. Para redescubrir su propia identidad, Europa debe volver a sus raíces, de tal forma que aprendiendo de sus propias experiencias históricas, ya sean legales, ya sean lingüísticas, ya sean sociales, configurar con bases sólidas su realidad de presente y de futuro.

Hace ya algunas décadas que asistimos a un proceso de unificación política que ha originado la realidad supraestatal que todos conocemos; de este proceso de unificación política y como una consecuencia ineludible de él, los constructores europeos han pretendido conformar de forma progresiva un orden normativo comunitario, que se configurase como la estructura jurídica que precisaba el nuevo ente público. Si la fase de unificación política está inconclusa, la de unificación jurídica está todavía en un estadio más temprano. El desarrollo de un derecho comunitario aplicable en toda la comunidad es todavía incipiente, pues es más lo que queda por legislar que lo que ya ha sido regulado.

La presencia del derecho romano en el devenir de la ciencia jurídica europea, amén de relevante, ha sido una constante histórica. Nadie discute el que uno de los rasgos propios definidores de la cultura común europea es el modo de concebir el derecho, así como el que una gran parte de su contenido se debe a la elaboración jurisprudencial del derecho romano, que tras la pérdida de vigencia histórica fue estudiado, analizado y transmitido, a través de la enseñanza autónoma, en todos los centros del saber europeos desde los maestros glosadores de Bolonia de fines del siglo $\mathrm{XI}^{9}$.

En el momento presente, en el que se trata de lograr un orden jurídico común en el seno de la Unión Europea, el derecho romano tiene todavía una función insustituible

\footnotetext{
${ }^{7}$ Vid. STEIN, P.G., El Derecho romano en la historia de Europa. Historia de una cultura jurídica, (trad. español C. Hornero y A. Romanos), Madrid, 2001.

${ }^{8}$ Vid. FERNÁNDEZ DE BUJÁN, F., Sistema contractual romano, $3^{\mathrm{a}}$ ed., Madrid, 2007, 481 ss.

${ }^{9}$ Vid. FERNÁNDEZ DE BUJÁN, Sistema contractual romano, cit., 491 ss.
} 
que cumplir: tanto en lo relativo a las construcciones jurídicas, patrimonio común de los juristas europeos, como en su espíritu, que ha sido y es el inspirador de los nuevos textos de derecho positivo.

El derecho privado romano invade la mayor parte de los actos ordinarios y extraordinarios de la vida de una persona. Si decimos propiedad o posesión; usufructo, hipoteca, servidumbre, derecho real; si entendemos el contrato o el delito; si pronunciamos compraventa, arrendamiento, mandato, sociedad; si nos referimos a acción o a proceso; si conocemos el sentido de la herencia, el testamento, el legado; si hacemos nuestros todos estos conceptos así como otras muchas instituciones jurídicas no mencionadas; si estamos familiarizados con ellos y sabemos lo que queremos decir; si conocemos básicamente su significado; si esto le sucede a cualquier habitante de cualquier territorio de Europa; y si esta cultura jurídica nos resulta cotidiana y normal; es porque en otro tiempo, desde los comienzos de siglo I, hace veintiún siglos, todo el viejo continente y sus habitantes, prácticamente ininterrumpidamente hasta hoy, han vivido en contacto diario con estas figuras e instituciones jurídicas, que a pesar de ser hoy patrimonio de la humanidad, especialmente de los ordenamientos jurídicos europeos, fueron concebidas, desarrolladas y reformadas por los juristas romanos hasta alcanzar una configuración imperecedera y universal.

El mismo reconocimiento que de las categorías jurídicas privadas, puede hacerse de innumerables conceptos de derecho público. La organización provincial que se estableció en el mundo romano los primeros siglos de nuestra era delimitó en gran manera el mapa político de la Europa que hoy conocemos. La forma de hacerse presente el poder político en el ámbito provincial y las facultades conferidas a los representantes de la metrópoli en los territorios sometidos al poder de Roma, se mantienen vigentes en numerosas instituciones regionales y provinciales con competencias territoriales.

Por poner algún ejemplo, muchas cuestiones, teóricas y prácticas, del derecho administrativo actual, como por ejemplo, en materia de obras públicas, concesiones y autorizaciones, orden público, policía central, local, funeraria, asistencia sanitaria, etc., leyes municipales, son realidades del derecho público romano que todavía tienen mucho que enseñar y tomarse como punto de referencia en el proceso de construcción supranacional de la Unión Europea. La verdad es que en ningún derecho que no sea el romano, se encuentra Europa a sí misma en la ordenación jurídica, política y administrativa de la sociedad.

Pudiera parecer que el derecho romano poco puede aportar hoy en día a la construcción de un nuevo derecho común europeo, pero no es así, pues sigue siendo posible defender su utilidad sobre todo porque en Europa no se va a inventar ningún ordenamiento nuevo strictu sensu sino que se va a partir de aquellas regulaciones comunes y tradicionales a todos sus pueblos, y esa regulación común mal que pese a muchos: por su conceptualización, su terminología, sus categorías jurídicas, su espíritu, no es otro que el ordenamiento romano recibido a través de muchos siglos de 
aplicación y estudio en el vieja Europa, desde donde ha sido exportado a tantos y tantos ordenamientos jurídicos como existen en Iberoamérica y que no son más que derecho romano tamizado por el derecho castellano o el francés o el portugués, todos ellos, sin duda, ordenamientos que se denominan de origen romanístico.

El derecho romano ha jugado y sigue jugando un papel básico en la configuración de Europa. No podemos olvidar que el ius commune fue derecho supletorio en toda Europa durante más de siete siglos; y no se puede pensar que ese modelo histórico, el ius commune sea un modelo superado del que no cabe extraer ninguna aportación. Pero no nos engañemos, ese derecho común sobrevive solamente hasta las distintas codificaciones civiles del siglo XIX, ahora bien, su pervivencia desde entonces se constata en el propio contenido de esos cuerpos legales por los cuales aún nos regimos; y esa regulación de las instituciones que se recogen en sus articulados es deudora de los conceptos y las instituciones del derecho romano fundido en el ius commune medieval.

Para una configuración plena y equilibrada desde un punto de vista especialmente jurídico, el derecho común europeo no debe ser inventado, porque además de ser materialmente imposible prescindir de las categorías jurídicas ya existentes, esenciales para armonizar y regular nuestras relaciones, se estaría creando un derecho artificial, superficial y por lo tanto con toda seguridad efímero. Además, sería un error crear un derecho resultado de lo que ha dado en llamarse ingeniería jurídica sobre la base de criterios inspirados en políticos tecnócratas.

Sin llegar a una exaltación enfermiza del pasado, y acogiéndose a la llamada moral del naufrago, que consiste en salvar aquello estrictamente necesario, se puede construir un derecho común europeo con unos sólidos cimientos basados en el derecho romano y en el ius commune medieval y moderno. Eso sí, es preciso adaptarlos a las nuevas necesidades del momento actual. La gran ventaja es que el tiempo ha sido un buen banco de pruebas que facilita unos materiales jurídicos contrastados y consolidados de los cuales sería una barbaridad prescindir a la hora de configurar Europa.

En definitiva, el derecho romano es la casa común del jurista europeo. En el derecho romano encuentra el jurista de derecho positivo principios y contenidos que le permiten criticar y analizar con profundidad y sobre todo con continuidad histórica las soluciones que a lo largo del tiempo se han dado a las distintas realidades jurídicas. No olvidemos que las necesidades humanas en orden a las relaciones jurídico-privadas siguen siendo hoy las mismas que en Roma, que supo plasmar en el plano jurídico, y de un modo insuperable, esas mismas relaciones.

Un ordenamiento jurídico europeo que tenga presente sus antecedentes históricos, que básicamente se centre en el derecho romano, nunca parecerá extraño a ninguno de sus pueblos en los que se pretende aplicar, pues cada uno de ellos podrá reconocer en ese ordenamiento jurídico unitario, parte de una historia pretérita común y parte de su propio derecho presente, enriquecido con lo mejor de la realidad actual de cada una de las otras tradiciones jurídicas nacionales. 
El derecho romano es el de mayor presencia histórica en la realidad política de nuestro tiempo. Hubo otros derechos en la antigüedad (griego, hebreo, egipcio, etc.), pero el que más ha influido en la formación jurídica de Europa ha sido el romano. Desde la fundación de Roma en el año 754 a.C. hasta la culminación recopilatoria del derecho clásico por Justiniano, que falleció en el año 565 d.C., son más de catorce siglos en los que el ordenamiento jurídico romano tuvo presencia en Europa, aún sin ésta existir técnicamente hablando.

$\mathrm{Si}$ a esta vigencia histórica se le añade la continuidad del Imperio Romano en Oriente hasta el siglo XV con su producción de derecho bizantino y si además sumamos la supervivencia legal del derecho romano en Occidente a partir del siglo XII, en su condición de ius commune por medio de la aplicación judicial y de las glosas hechas a los textos justinianeos por los glosadores y los comentaristas, hasta llegar a la cristalización de los principios y las instituciones del derecho romano en los distintos procesos codificadores de las diferentes naciones del continente, se puede afirmar que la historia jurídica europea es, en una gran parte, la historia del surgimiento, vigencia y supervivencia del ordenamiento jurídico romano.

En definitiva, el derecho romano contribuyó a la elaboración de las codificaciones civiles europeas, no solo a través de su creación jurisprudencial, sino también a través del proceso de estudio, exégesis y sistematización que constituyó su recepción en la ciencia jurídica europea. Con base en todo lo anterior, podemos apuntar que en nuestras relaciones con los países de la Europa continental, sobre todo, el derecho romano puede ser un buen punto de conexión entre todos sus sistemas jurídicos, pues al ser la inmensa mayorías de ellos de base romanística, resulta más fácil su conocimiento y comprensión, a la vez que facilita el estudio del derecho comparado, pues construir la historia jurídica europea es reconstruir, en gran medida, la historia del derecho romano en Europa.

En el ámbito de la Unión Europea las iniciativas de leyes uniformes se encuentran con el obstáculo de la diversidad del lenguaje jurídico. Pues bien, la lengua será probablemente el inglés pero el derecho romano ha de servir sobre todo como base de las nociones jurídicas comunes que permitan facilitar el dialogo y construir la regla "igual" para todos. Todo ello queda gráficamente expresado con una frase que aparece en la exposición de motivos del Código de Napoleón, atribuida a uno de sus autores, Portalís, : "Hemos levantado en parte nuestro edificio legislativo con los materiales que nos han transmitido los jurisconsultos de Roma. Roma ha subyugado a Europa con sus armas y lo ha civilizado con sus leyes".

Es decir, "A derecho escrito, que se compone de leyes romanas, ha civilizado E uropa" 10 . A ello se debe añadir que el derecho romano ha influido tanto en el orden jurídico europeo que se ha convertido en un utilísimo auxiliar interpretativo del derecho positivo, por cuanto los códigos no representan sino el punto histórico final en la evolución de un principio

\footnotetext{
${ }^{10}$ PORTALIS, J.E.M., Discurso preliminar al Código civil francés (trad. I. Cremades y L. Gutiérrez-Masson), Madrid, 1997, 50.
} 
jurídico, el cual será bien comprendido cuando se analice la raíz remota de donde proceda. Además, todo cuanto tenemos no deteriorado del derecho civil y sin necesitar continuos retoques lo hemos recibido del derecho romano tal como nos lo dejaron los autores del ius commune. Después no hemos hecho sino compilar, codificar, conceptualizar, clasificar, sistematizar y fabricar dogmas jurídicos ${ }^{11}$.

Tal ha sido la importancia del derecho romano en la actual configuración europea, al menos desde el punto de vista jurídico, que a medida que se avanza en la consolidación efectiva de la Unión Europea se observa la urgente necesidad de superar la dispersión legal de los distintos sistemas normativos de los estados que la conforman. Un ejemplo muy representativo es el Anteproyecto de Código Europeo de Contratos ${ }^{12}$ que se enmarca en la tendencia de unificación legal perseguida a lo largo de todo el siglo veinte y que esperemos se consolide en el veintiuno. Dicho Anteproyecto, muy avanzado en su elaboración, tiene como fin primordial superar las diferencias y contrastes de los distintos ordenamientos europeos al objeto de conseguir una eficacia real.

A lo largo de todo el proceso de elaboración del Código Europeo de Contratos se ha puesto de manifiesto la necesidad de huir de la artificiosidad y buscar, por el contrario, unas bases comunes que permitan aunar a los distintos sistemas. Por inverosímil que parezca, amén de mantener como estandarte el principio de la autonomía de la voluntad, propio de todos los ordenamientos europeos, destaca el origen e influencia del derecho romano y de su proyección histórica en la inmensa mayoría de los sistemas de derecho privado que ahora se pretenden armonizar (unificar). La influencia se va a producir irremediablemente porque el mencionado Código Europeo de Contratos se ha elaborado por una Comisión de juristas, sobre los que pesa, lo quieran o no, una importante formación romanística, e incluso alguno ha sido romanista de reconocido prestigio como $\mathrm{F}$. Wieacker ${ }^{13}$.

Por otro lado, se ha tomado como punto de referencia y auxilio de las discusiones el Código Givil italiano, concretamente su libro $4^{\circ}$, a propuesta del Prof. G. Gandolfi, para proceder a plasmar, modificar, corregir o ampliar todo lo que sea necesario. Pues bien, lo que resulta innegable es que el Código civil italiano es de base romanística, por ello el lenguaje, los términos y los conceptos van a ser comunes a la inmensa mayoría de los ordenamientos jurídicos europeos, pues el repertorio de conceptos básicos del derecho privado europeo tradicionalmente proceden del derecho romano.

Asimismo, la jurisprudencia romana nos enseñó que el jurista debe apegarse a la resolución del problema concreto, liberándose en la medida de lo posible de los excesos

\footnotetext{
${ }^{11}$ VALLET DE GOYTISOLO,J., Metodología jurídica, Madrid, 1988, 125.

${ }^{12}$ Vid. VATTIER FUENZALIDA, G., El Derecho europeo de contratos y el anteproyecto de Pavía, en A.D.C., tomo LXI, fasc. IV, 2008, 1841 ss.

${ }^{13}$ Vid.JURISTAS UNIVERSALES, Juristas del s. XX, (R. DOMINGO, ed.) vol. IV, Madrid, 2004, s.v. Franz Wieacker, 538 ss.
} 
teóricos, por ello es apreciable que el Código Europeo de Contratos busque soluciones prácticas prescindiendo de los grandes enunciados dogmáticos.

Evidentemente, los codificadores no solamente se apoyan en los códigos de la Europa continental, principalmente en el italiano, sino que además tienen en cuenta la codificación del derecho de contratos vigente británico representado en el Contract Code del Profesor McGregor, pues el objetivo, no se olvide, es superar la dualidad del civil law y el common law para obtener la unificación efectiva que supere el pluralismo legal en materia de obligaciones y contratos, y a la vez no presente especiales dificultades su aplicación en ninguno de los países miembros de la Unión.

En consecuencia, con la elaboración del Código Europeo de Contratos ${ }^{14}$ se está consolidando la vieja tendencia de no romper con la influencia de la historia en el proceso de formación del derecho europeo. Nos encontramos, pues, ante una manifestación tardía de todo el proceso codificador que comenzó allá en el siglo diecinueve, continuó en el veinte, y ahora, en el veintiuno, con carácter supranacional. Este proceso viene a confirmar aquel otro que comenzó con la compilación del derecho privado romano en el Corpus I uris Civilis, su posterior estudio por los glosadores, comentaristas, humanistas, racionalistas, etc. hasta llegar a la Pandectística y a la Escuela Histórica alemana y posteriores codificaciones civiles europeas.

A los romanistas nos gustaría, aunque somos conscientes de que no se va a producir, que en el futuro Código Europeo de Contratos se hiciera alusión directa y sin complejos a todas las influencias recibidas del derecho romano. Obviamente, nuestro derecho vigente tiene su antecedente en el derecho romano y ejemplos de ello pueden ponerse, pero un detalle muy gráfico se deduce de la legislación más reciente si acudimos ad exemplum al derecho catalán, pues en sus últimas leyes pueden leerse referencias explícitas al derecho romano.

Así, en el Código de sucesiones por causa de muerte en el derecho civil de Cataluña, en su Preámbulo, se dice expresamente que "No se modifican, por lo tanto, los grandes principios propios del D erecho romano, tan arraigados en el D erecho sucesorio catalán" ${ }^{15}$. En la Ley que regula los derechos reales ${ }^{16}$, también en el Preámbulo, se recuerda que aún existen instituciones de origen romano, por ello se "mantiene, actualizadas profundamente, instituciones tradicionales en el derecho catalán, algunas de ascendencia romana, como son el usufructo y sus diminutivos o las servidumbres"; e igualmente en la Ley por la que se crea el Código civil de Cataluña ${ }^{17}$ hace en varias ocasiones referencia al derecho romano para reconocer el origen remoto y, a veces superado, de algunas de sus instituciones jurídicas.

En fin, lo que se pretende es recordar que el ordenamiento jurídico romano es el inspirador de muchos de los principios del derecho europeo; no obstante, su

\footnotetext{
${ }^{14}$ Vid. texto en Código Europeo de Contratos. Academia de Iusprivatistas Europeos (Pavía), 2 tomos, (dirts. C. Vattier et alii), Madrid, 2003.

${ }^{15}$ Ley 40/1991, de 30 diciembre: Código de sucesiones por causa de muerte en el Derecho Civil de Cataluña.

${ }^{16}$ Ley 5/2006, de 10 de mayo, del Libro Quinto del Código Civil de Cataluña, relativo a los derechos reales.

${ }^{17}$ Ley 29/2002, de 30 de diciembre, primera Ley del Código civil de Cataluña.
} 
recepción viene matizada por el devenir histórico, de tal modo que una cosa es que los grandes principios ondeen sobre la legislación y otra bien distinta que la regulación del particularizado casuismo sea idéntica. El derecho romano debido a su implantación en prácticamente todos los planes de estudios jurídicos del mundo, eso sí, con intensidad y objetivos distintos, se ha convertido en una ciencia supranacional cuya importancia crece en proporción directa a las divergencias que existan entre los sistemas jurídicos, en este caso, europeos. Se trata del elemento histórico necesario para la interpretación de los ordenamientos europeos continentales.

No olvidamos, obviamente, que el derecho romano ha influido más en unas zonas que en otras del derecho privado, así, esa influencia es más acusada en materia de obligaciones y contratos y sucesiones que en materia de familia por ejemplo, de ahí su importancia en relación con el Código Europeo de Contratos ${ }^{18}$. En consecuencia, y aunque parezca que hacemos apología de la ciencia jurídica romana, conviene recordar que el saber humano no es más que la historia de la actividad del espíritu, y su transmisión solamente se obtiene a través de un exacto inventario de conceptos esenciales ${ }^{19}$. Las categorías jurídicas son como las categorías lógicas que sólo cambiarán cuando cambie la naturaleza del hombre ${ }^{20}$.

\section{O DIREITO ROMANO COMO ELEMENTO DE HARMONIZAÇÃO DO NOVO DIREITO COMUM EUROPEU}

Resumo: No âmbito da União Europeia, o Direito compõe-se de uma gama de ordenamentos jurídicos autônomos que demandam uma aproximação entre si. Como todos estes ordenamentos são de base romanística, especialmente os da Europa ocidental, o Direito Romano deve ter um papel transcendental na sua futura harmonização, sem que por seu intermédio seja suprimida a diversidade jurídica própria de cada povo que integra a referida união.

Palavras-chave: União Europeia. Harmonização jurídica. Direito Romano. Direito comum europeu.

\footnotetext{
${ }^{18} \mathrm{Si}$ el prestigioso historiador italiano P. GROSSI, La propiedad y las propiedades. Un análisis histórico, (traducción y "Prólogo para civilistas" de A. M. López y López), Madrid, 1992, 123 ss., veía de forma imaginaria al Code civil napoleónico como un palimpsesto jurídico, lo mismo podríamos decir del Código Europeo de Contratos por cuanto si por palimpsesto entendemos el "manuscrito antiguo que conserva huellas de una escritura anterior borrada artificialmente" (definición diccionario RAE), podría decirse que en este Proyecto, en algunos de sus apartados, si analizamos las disposiciones jurídicas que subyacen y que artificialmente se han querido borrar, encontramos el derecho romano en su máximo esplendor.

${ }^{19}$ Vid. CASAVOLA, F.P., L'educazione del giurista tra memoria e ragione, INDEX, 19, 1991, 325.

${ }^{20}$ Sull'Europa, sull'insegnamento e l'applicazione del diritto romano (1922-1974): citazioni scelte di Giorgio La Pira, a cura di P. CATALANO, INDEX, 23, 1995, 32.
} 